\title{
Biomassa microbiana em amostras de solos secadas ao ar e reumedecidas ${ }^{(1)}$
}

\author{
Antônio Samarão Gonçalves ${ }^{(2)}$, Marcela Teixeira Monteiro(3) ${ }^{(3)}$ José Guilherme Marinho Guerra( ${ }^{(4)}$ e Helvécio De-Polli(3)
}

\begin{abstract}
Resumo - O objetivo do trabalho foi avaliar a viabilidade do condicionamento de amostras como terra fina secada ao ar (TFSA) por curto período, para a determinação do carbono da biomassa microbiana (BMS-C), pelo método da fumigação-extração, e verificar a respiração microbiana basal (RB) do solo. $\mathrm{O}$ condicionamento como TFSA, procedendo-se à fumigação para a análise da BMS-C imediatamente ou 24 horas após o reumedecimento, proporcionou valores de BMS-C para os solos Podzólicos, Latossolo Vermelho-Amarelo álico e Orgânico, semelhantes aos valores dos seus controles. Os solos Glei Pouco Húmico e Vertissolo apresentaram valores de BMS-C similares aos do controle a partir de 24 horas de incubação; o solo Planossolo arenoso apresentou valores similares aos do controle com 72 horas, e a Rendizina, com 168 horas de incubação. Na maioria dos solos, a RB determinada na TFSA apresentou valores maiores do que os do tratamento-controle, quando avaliada imediatamente ou 24 horas após o reumedecimento a $60 \%$ da capacidade máxima de retenção de água, seguida de queda e manutenção em níveis semelhantes ao do controle nos períodos subseqüentes. O pré-condicionamento, de curta duração, como TFSA, é promissor para a determinação da BMS-C, quando níveis e períodos adequados de reumedecimento são adotados.
\end{abstract}

Termos para indexação: carbono, fumigação do solo, umidade do solo.

\section{Microbial biomass in air dried and rewetted soil samples}

\begin{abstract}
The objective of this work was to evaluate the utilization of short term air dried soil samples in a determination of soil microbial biomass (SMB-C), by a fumigation-extraction method, and soil microbial basal respiration (BR). Zero time or 24 hours rewetting incubation period before fumigation procedure gave values of SMB-C similar to those of the control for the Podzolic soils, Allic Red-Yellow Latosol and Organic soil. Low Humic Gley and Vertisol soils gave values of SMB-C similar to those of the control for periods of incubation equal or higher than 24 hours. Planosol (sandy soil) and Rendzina soils gave values of SMB-C similar to the control for periods of incubation equal to 72 and 168 hours, respectively. For the majority of soil tested, zero time or 24 hours rewetting incubation period before $\mathrm{BR}$ incubation procedure gave higher respiration values than those of the control, and decreasing to values similar to those of the control for 72 and 168 hours of rewetting incubation period at $60 \%$ of the water holding capacity. In conclusion, the evaluation of SMB-C in short term air dried and rewetted soil samples is feasible according to proper moisture levels and periods of pre-incubation.
\end{abstract}

Index terms: carbon, soil fumigation, soil moisture.

(1) Aceito para publicação em 18 de outubro de 2001 . Extraído da dissertação de mestrado apresentada pelo primeiro autor à Universidade Federal Rural do Rio de Janeiro, Seropédica, RJ. Parcialmente financiado pelo CNPq.

(2) Av. Ministro Fernando Costa, 1004, loja 4, CEP 23890-000 Seropédica, RJ. Bolsista do CNPq. E-mail: samarao@ig.com.br

(3) Embrapa-Centro Nacional de Pesquisa de Agrobiologia (CNPAB), Caixa Postal 74505, CEP 23851-970 Seropédica, RJ. Bolsista do CNPq. E-mail: marcelatm@bol.com.br, depolli@cnpab.embrapa.br

(4)Embrapa-CNPAB. E-mail: gmguerra@cnpab.embrapa.br

\section{Introdução}

A biomassa microbiana do solo (BMS) é o principal componente do subsistema de decompositores, que regula a ciclagem de nutrientes, o fluxo de energia, a produtividade das plantas e dos ecossistemas, e portanto, a medição deste compartimento e sua atividade são relevantes para a conservação dos solos (Sparling, 1992; Wardle \& Ghani, 1995; Wardle, 1998; De-Polli \& Guerra, 1999). 
Um dos métodos predominantes atualmente na determinação da BMS é o da fumigação-extração (Vance et al., 1987) em que se estima o C contido na biomassa dos microrganismos (BMS-C). O método em si está relativamente bem padronizado em seu protocolo laboratorial por diferentes usuários. O mesmo não ocorre em relação à condição de transporte, armazenagem e pré-condicionamento da amostra anteriormente à fumigação. Um fator relevante no pré-preparo das amostras é a padronização, ou não, da umidade do solo. Como a umidade pode interferir na eficiência do clorofórmio como agente fumigante (Badalucco et al., 1997), tem sido comum a correção da umidade do solo antes da fumigação para obtenção de valores em torno de 40 a $70 \%$ da capacidade máxima de retenção de água do solo. Porém, há que se considerar o possível impacto da adição de água em uma amostra de solo que foi coletado com baixo teor de umidade nas determinações da BMS-C (Gestel et al., 1992, 1993). A diminuição da umidade no ambiente externo acarreta aumento da concentração de solutos intracelulares e, com o solo muito seco, pode provocar o rompimento e morte das células microbianas (Kieft et al., 1987). Valores altos de BMS-C encontrados logo após o reumedecimento de amostras podem ser decorrentes do fluxo de atividade da BMS no reservatório de matéria orgânica do solo, que se encontra sujeito a pronta mineralização (Franzluebbers et al., 1996). Neste caso, os microrganismos remanescentes utilizam como substrato as células dos microrganismos mortos, multiplicandose até que o substrato esteja perto da exaustão, alcançando número máximo, e logo depois, o número de microrganismos vivos decresce (Joergensen et al., 1990). A secagem ao ar pode também interferir na análise de nutriente disponível para fins de interpretação de fertilidade do solo. Srivastava (1998) detectou significativos aumentos de $\mathrm{N}$ e P extraíveis após a secagem de oito Ultisols tropicais indianos. Mesmo em condições de campo, ciclos de secagem e umedecimento do solo podem afetar o conteúdo de C orgânico dissolvido do solo, conforme resultados encontrados por Lundquist et al. (1999) em solos da Califórnia, Estados Unidos. Franzluebbers et al. (1996, 2000) e Franzluebbers (1999) observaram que o condicionamento de amostras de solo na forma de terra fina secada ao ar (TFSA) é um procedimento passí- vel de ser adotado na determinação da BMS-C. A secagem ao ar da amostra acarreta facilidade na operacionalização das análises de BMS, e torna-se importante caracterizar o impacto do condicionamento de curta duração da amostra na forma de TFSA sobre o $\mathrm{C}$ da biomassa microbiana do solo.

O objetivo deste trabalho foi avaliar a viabilidade do preparo de amostras de solos na forma de terra fina secada ao ar, para determinar o $\mathrm{C}$ da biomassa microbiana e a respiração microbiana basal do solo.

\section{Material e Métodos}

Amostras de dez classes de solos apresentando características físicas e químicas distintas (Tabela 1), determinadas como descrito no Manual de Métodos de Análise de Solo (Embrapa, 1979), foram coletadas em áreas com cobertura vegetal de pastagens, no Estado do Rio de Janeiro. As coletas foram realizadas em agosto de 1998, em um período com estiagem, na profundidade de $0-10 \mathrm{~cm}$, após remoção dos resíduos orgânicos superficiais. Cada amostra composta foi oriunda de cinco subamostras. As amostras compostas foram transportadas para o laboratório, determinando-se a capacidade máxima de retenção de água, e, posteriormente, divididas em duas partes. Uma parte constituiu o tratamento-controle (método de referência para o condicionamento de amostra) respectivo de cada classe de solo, onde as amostras não sofreram secagem e nem peneiramento, e às quais foram adicionadas quantidades de água para elevar a umidade ao nível de $60 \%$ da capacidade de retenção máxima, permanecendo as amostras em sacos de polietileno por três dias; depois, determinaram-se o $\mathrm{C}$ contido na biomassa dos microrganismos (BMS-C) e a respiração microbiana basal (RB); os controles foram utilizados nos dois experimentos conduzidos conforme descrição posterior. A outra parte das amostras foi secada ao ar, à sombra, durante sete dias, destorroada e peneirada a $2 \mathrm{~mm}$, para a obtenção de terra fina secada ao ar (TFSA). Com estas amostras, realizaram-se dois experimentos seqüenciais de laboratório, empregando-se o delineamento de blocos ao acaso, em esquema fatorial 10x5 (classe de solo x período de incubação de amostra condicionada na forma de TFSA reumedecida no experimento 1 ; e classe de solo x nível de umidade na TFSA no experimento 2), com três repetições.

No experimento 1 os tratamentos constaram das classes de solo e períodos de incubação (0, 24, 72 e 168 horas) antes da fumigação, para determinar a BMS-C, e antes da incubação, para RB das amostras condicionadas na forma de TFSA, além do tratamento-controle já descrito anteriormente. No início do experimento, a umidade das amos- 


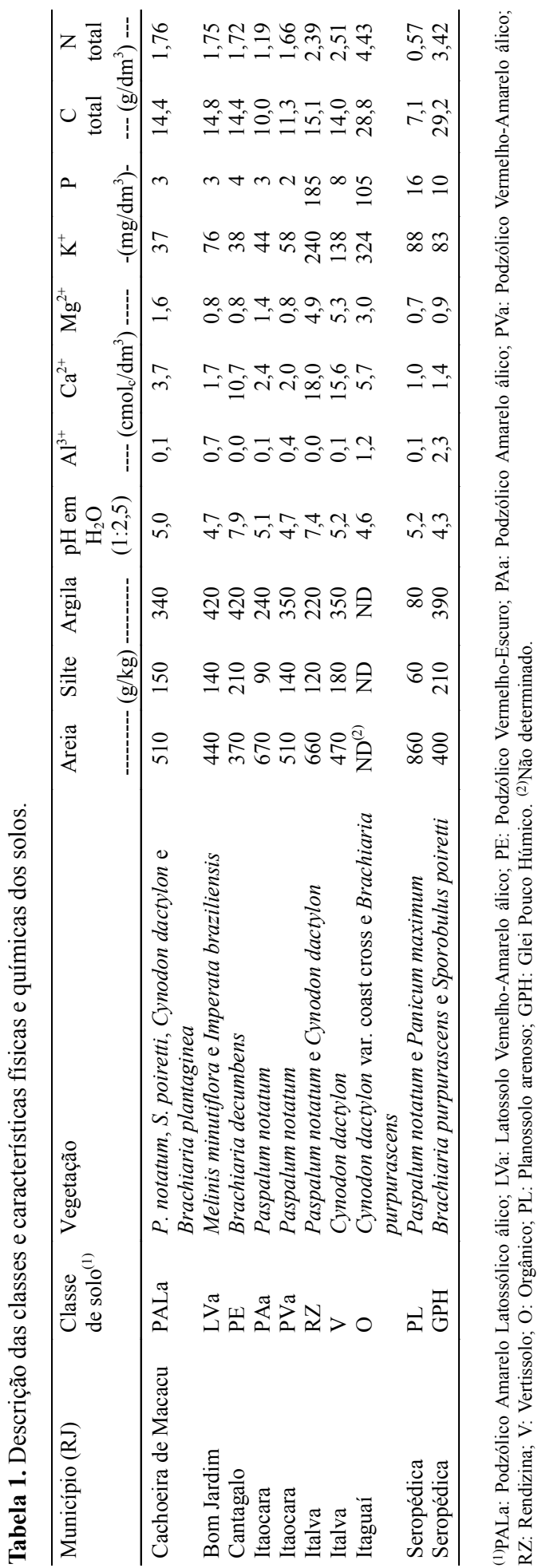

tras foi reposta até $60 \%$ da capacidade máxima de retenção de água, e foi mantida durante os períodos de incubação.

No experimento 2, nas amostras das diferentes classes de solo condicionadas na forma de TFSA, aplicaram-se tratamentos relativos a níveis de reumedecimento $(0,25$, 50 e $75 \%$ da capacidade máxima de retenção de água de cada solo), além do tratamento-controle já descrito. A BMS-C e a RB foram estimadas logo após o umedecimento das amostras.

A determinação da BMS-C foi feita por fumigação-extração, conforme método proposto por Vance et al. (1987), e descrita em De-Polli \& Guerra (1999). Determinou-se, ainda, a RB, obtida pela incubação das amostras com captura de $\mathrm{CO}_{2}$ em $\mathrm{NaOH}$ durante cinco dias, pela adaptação do método da fumigação-incubação, proposto por Jenkinson \& Powlson (1976). A capacidade máxima de retenção de água da TFSA foi determinada em coluna contínua de terra, a partir do preenchimento de uma proveta de $500 \mathrm{~cm}^{3}$ com TFSA. Utilizaram-se amostras triplicadas de cada classe de solo. Adicionou-se água em volume valorado necessário para umedecer a coluna de solo, de tal forma que a frente de umedecimento estacionasse antes do fundo da proveta. Para minimizar a perda de água por evaporação, cobriu-se a boca da proveta de forma não-hermética, permitindo, assim, o efeito normal da pressão atmosférica. Considerou-se que a TFSA estava na capacidade máxima de retenção de água quando a frente de umedecimento encontrava-se praticamente estacionada em período aproximado de 24 horas. Logo após, foram retirados $20 \mathrm{~g}$ de terra da coluna, para determinação da umidade gravimétrica por meio de secagem em estufa de ventilação forçada, com temperatura de $105^{\circ} \mathrm{C}$.

Em decorrência da heterogeneidade observada entre as variâncias das classes de solos, realizou-se a análise de variância, determinando-se a probabilidade pelo teste F, e o teste de Tukey, para testar as médias de tratamentos, em cada classe de solo. Para interpretação dos resultados de BMS-C e RB utilizou-se a comparação das médias, dentro de cada classe, e as análises de correlação simples envolvendo todas as classes de solo para cada período de reumedecimento ou para cada nível de umidade em relação aos seus respectivos controles. Estas análises de correlação foram realizadas a fim de estimar o grau de relação dos tratamentos impostos comparados com o tratamento considerado padrão (controle), sendo feita a comparação dos coeficientes de correlação através do teste $t$ de Fisher.

\section{Resultados e Discussão}

Os valores de BMS-C de amostras de diferentes classes foram influenciados pelo período de incubação com umidade corrigida antes da fumigação da 
TFSA e houve diversidade no comportamento da BMS-C em todas as classes de solo avaliadas em relação ao procedimento adotado como referência (tratamento-controle) (Tabela 2). Em decorrência desta diversidade detectada entre os fatores classe de solo e período de incubação da TFSA para estimativa da BMS-C, e considerando, conjuntamente, a interpretação dos testes de média e dos coeficientes de correlação, as classes de solo foram separadas em diferentes grupos. Os valores de BMS-C encontrados nas amostras dos solos Podzólicos, LVa e O, imediatamente e 24 horas após o reumedecimento da TFSA não diferiram dos seus respectivos controles. A amostra de GPH e de V apresentaram valores de BMS-C na TFSA similares ao procedimento de referência para determinação deste parâmetro, a partir de 24 horas de incubação anteriormente ao processo de fumigação. As análises de correlação, envolvendo o controle e os diferentes períodos de incubação (reumedecimento) da TFSA antes da fumigação das amostras, apresentaram coeficientes altamente significativos $(\mathrm{p}<0,001)$, independentemente do período de incubação (Tabela 2).

Somente as amostras de PL e RZ apresentaram períodos relativamente longos, respectivamente, de
72 e 168 horas de incubação, para que a BMS-C da TFSA tenha alcançado valores similares aos respectivos controles. O solo PL apresenta altos teores de areia e muito baixo teor de argila e C orgânico (Tabela 1), características da fração mineralógica dos solos que podem afetar a sobrevivência de microrganismos sob condições de dessecação (Wardle, 1992; Gestel et al., 1993). Portanto, o tempo de 72 horas seria necessário para a recuperação do crescimento microbiano e aumento da biomassa. A queda inicial detectada nos valores da BMS-C na TFSA do PL, em comparação com o controle, pode estar associada à mortalidade dos microrganismos, de tal magnitude, que a microbiota remanescente necessitou, após o umedecimento, de um período relativamente longo para alcançar o nível do tratamento-controle, em face da reduzida disponibilidade de fontes de energia e de crescimento neste solo. Deve-se salientar que os valores de BMS-C no tratamento-controle do PL mostraram-se maiores do que os valores encontrados por Rodrigues et al. (1994), com amostras desta mesma classe de solo, e portanto, os resultados obtidos imediatamente e 24 horas após o início de incubação são mais condizentes com os valores normalmente encontrados no PL. A amostra de RZ, diferentemen-

Tabela 2. Carbono da biomassa microbiana ( $\mu \mathrm{g}$ de carbono por g de solo) e da respiração microbiana basal ( $\mu \mathrm{g}$ de carbono- $\mathrm{CO}_{2}$ por g de solo, por hora) em amostras de diferentes classes de solo condicionadas na forma de terra fina secada ao ar, reumedecidas e mantidas em incubação por diferentes períodos (horas) antes da fumigação ou da medição da respiração e coeficientes de correlação $(\mathrm{r})^{(1)}$.

\begin{tabular}{|c|c|c|c|c|c|c|c|c|c|c|}
\hline \multirow[t]{3}{*}{ Solo $^{(2)}$} & \multicolumn{5}{|c|}{ Biomassa microbiana } & \multicolumn{5}{|c|}{ Respiração microbiana basal } \\
\hline & \multirow[t]{2}{*}{ Controle $^{(3)}$} & \multicolumn{4}{|c|}{$\begin{array}{l}\text { Período do reumedecimento } \\
\text { antes da fumigação }\end{array}$} & \multirow[t]{2}{*}{ Controle $^{(3)}$} & \multicolumn{4}{|c|}{ Período do reumedecimento } \\
\hline & & 0 & 24 & 72 & 168 & & 0 & 24 & 72 & 168 \\
\hline &.- & $-\cdots$ & $-(\mu \mathrm{g} / \mathrm{g})$ & -------- & $----\cdot$ & -5 & - & $(\mu \mathrm{g} / \mathrm{g}$ & & --. \\
\hline PALa & $309 a$ & $278 \mathrm{a}$ & $359 \mathrm{a}$ & $215 \mathrm{a}$ & $333 \mathrm{a}$ & $1,01 \mathrm{a}$ & $1,16 \mathrm{a}$ & $1,28 \mathrm{a}$ & $0,59 \mathrm{a}$ & $0,53 \mathrm{a}$ \\
\hline LVa & $334 \mathrm{ab}$ & $310 \mathrm{ab}$ & $267 b c$ & $479 \mathrm{a}$ & $172 \mathrm{c}$ & $0,70 \mathrm{~b}$ & $1,52 \mathrm{a}$ & $1,47 \mathrm{a}$ & $0,62 b$ & $0,74 \mathrm{~b}$ \\
\hline PE & $336 a b$ & $271 b c$ & $204 \mathrm{~cd}$ & $391 \mathrm{a}$ & $144 d$ & $0,98 \mathrm{ab}$ & $1,28 \mathrm{ab}$ & $1,70 \mathrm{a}$ & $0,88 \mathrm{~b}$ & $1,01 \mathrm{ab}$ \\
\hline PAa & $389 a$ & $371 \mathrm{a}$ & $343 a b$ & $431 \mathrm{a}$ & $262 b$ & $0,69 b$ & $1,53 \mathrm{a}$ & $1,36 \mathrm{a}$ & $0,62 b$ & $0,69 \mathrm{~b}$ \\
\hline PVa & $358 b$ & $343 b$ & $444 \mathrm{ab}$ & $613 a$ & $286 b$ & $0,95 b$ & $1,75 \mathrm{a}$ & $1,65 \mathrm{a}$ & $0,93 b$ & $0,72 b$ \\
\hline $\mathrm{RZ}$ & $409 b$ & $598 \mathrm{a}$ & $531 \mathrm{a}$ & $553 a$ & $425 b$ & $0,81 b$ & $1,54 \mathrm{a}$ & $1,59 \mathrm{a}$ & $0,97 \mathrm{~b}$ & $0,86 \mathrm{~b}$ \\
\hline V & $583 b$ & $787 a$ & $680 \mathrm{ab}$ & $697 \mathrm{ab}$ & $680 \mathrm{ab}$ & $0,67 b$ & $1,85 \mathrm{a}$ & $1,28 \mathrm{a}$ & $0,74 \mathrm{~b}$ & $0,53 b$ \\
\hline $\mathrm{O}$ & $562 \mathrm{ab}$ & $596 a$ & $535 \mathrm{ab}$ & $575 \mathrm{ab}$ & $413 b$ & $1,75 \mathrm{a}$ & $2,24 \mathrm{a}$ & $1,82 \mathrm{a}$ & $1,10 \mathrm{~b}$ & $0,93 \mathrm{~b}$ \\
\hline PL & $299 a$ & $169 b c$ & $138 \mathrm{~cd}$ & $225 \mathrm{ab}$ & $100 d$ & $0,79 \mathrm{ab}$ & $0,98 \mathrm{a}$ & $0,84 \mathrm{ab}$ & $0,79 \mathrm{ab}$ & $0,38 b$ \\
\hline GPH & $826 \mathrm{~b}$ & $1.319 \mathrm{a}$ & $1.049 \mathrm{ab}$ & $1.008 \mathrm{ab}$ & $1.039 \mathrm{ab}$ & $1,19 \mathrm{~b}$ & $2,34 \mathrm{a}$ & $1,87 \mathrm{a}$ & $0,82 \mathrm{c}$ & $0,98 \mathrm{bc}$ \\
\hline $\mathrm{r}$ & 1,00 & $0,95 * * *$ & $0,92 * * *$ & $0,79 * * *$ & $0,95 * * *$ & 1,00 & $0,55^{* *}$ & $0,48^{*}$ & $0,49 *$ & $0,52 * *$ \\
\hline
\end{tabular}

${ }^{(1)}$ Valores em uma mesma linha seguidos de letras iguais não diferem entre si pelo teste de Tukey, a 5\% de probabilidade. ${ }^{(2)}$ PALa: Podzólico Amarelo Latossólico álico; LVa: Latossolo Vemelho-Amarelo álico; PE: Podzólico Vermelho-Escuro; PAa: Podzólico Amarelo álico; PVa: Podzólico Vermelho-Amarelo álico; RZ: Rendizina; V: Vertissolo; O: Orgânico; PL: Planossolo arenoso; GPH: Glei Pouco Húmico. ${ }^{(3)}$ Amostras que não sofreram dessecação e com umidade corrigida a $60 \%$ da capacidade máxima de retenção. ***, ** e *Significativo a $0,1 \%$, a $1 \%$ e a $5 \%$ de probabilidade, respectivamente. 
te de PL, apresentou valores de BMS-C e RB, nos períodos iniciais de incubação, maiores do que os do controle. Como o solo RZ encontra-se localizado em uma região sujeita a longos períodos de estiagem e apresenta altos teores de C e de N (Tabela 1), podese especular que a sobrevivência dos microrganismos neste solo esteja associada à rápida capacidade de crescimento, aproveitando os pulsos concentrados de água de chuva e a disponibilidade de nutrientes.

O condicionamento de amostras na forma de TFSA para estimativa da BMS-C, na maioria das classes de solos aqui avaliadas, distintamente do preconizado por Horwath \& Paul (1994), não acarretou diferença nos resultados obtidos, em comparação com amostras que não sofreram tal preparo. Porém, evidenciam que o período de incubação (reumedecimento) da TFSA influencia a estimativa deste parâmetro. Em concordância com estas observações, Franzluebbers et al. (1996) concluíram que períodos de 1 e 15 dias de incubação de amostras de solos de região não tropical, condicionadas pela secagem e pelo umedecimento subseqüente, propiciaram a obtenção de valores de BMS-C similares aos do controle sem dessecação. Posteriormente, Franzluebbers (1999) relatou que, tanto a secagem como o peneiramento, seguidos do umedecimento e incubação por dez dias proporcionaram valores de BMS-C semelhantes aos determinados em amostras intactas com teores de umidade naturais.

Assim como detectado para a BMS-C, a estimativa da respiração basal (RB) em amostras condicionadas na forma de TFSA variou de acordo com a classe de solo e o período de incubação, se comparadas com o tratamento-controle relativo a cada amostra (Tabela 2), o que denota que a microbiota de cada tipo de solo apresenta características próprias, como destacado por Gestel et al. (1993). Para a maior parte dos solos avaliados, a RB determinada na TFSA apresentou valores maiores do que o tratamento-controle, quando avaliada imediatamente ou 24 horas após o início de incubação, seguida de queda e manutenção em níveis semelhantes ao controle nos períodos subseqüentes. Semelhante pulso de atividade também foi encontrado por Colores et al. (1996).
Na maioria das amostras avaliadas, distintamente dos resultados encontrados com relação à BMS-C, notou-se que a determinação da RB na TFSA 72 horas após o reumedecimento proporcionou valores similares aos controles respectivos de cada classe de solo, exceto nas classes $\mathrm{O}$ e GPH, sendo, os valores, nestas duas classes, $37 \%$ e $31 \%$ menores, respectivamente, do que os controles (Tabela 2). Destaca-se que, em condições naturais, ambos os solos apresentam drenagem imperfeita, mantendo-se encharcados durante longos períodos do ano, e, por conseguinte, acarretando acumulação de material orgânico em estágio incipiente de decomposição, cuja mineralização passa, provavelmente, por um período de adaptação à condição de maior aeração imposta pela metodologia.

Conquanto os coeficientes das análises de correlação referentes a RB envolvendo as variáveis controle das amostras dos solos e os diferentes períodos de incubação tenham alcançado significância, os valores foram relativamente baixos, diferentemente do observado quanto à BMS-C (Tabela 2). Logo, a perspectiva de utilização do condicionamento de amostras de solo na forma de TFSA para determinação da RB, embora possível, deve ser analisada com o devido cuidado e após padronização para cada situação específica.

O condicionamento na forma de TFSA, sem o reumedecimento anterior à fumigação, acarretou, geralmente, queda nos valores de BMS-C, atingindo redução média de $51 \%$, com variação de 19 a $76 \%$, respectivamente, nas amostras dos solos GPH e PL (Tabela 3). Botner (1985) observou que a dessecação do solo reduziu a biomassa microbiana em até $75 \%$ do valor original, porém o umedecimento subseqüente proporcionou valores semelhantes aos encontrados antes da secagem.

Decompondo o efeito dos níveis de umidade nas amostras das diferentes classes de solo, destaca-se que a reposição até o nível de $25 \%$ da capacidade de retenção máxima proporcionou a obtenção de valores de BMS-C similares aos respectivos controles das diferentes classes de solo avaliadas, exceto nas amostras RZ e GPH (Tabela 3). Os níveis de 50 e $75 \%$ de umidade também não proporcionaram diferenças 
significativas na BMS-C em relação ao tratamentocontrole de cada classe de solo, exceto na amostra GPH em ambos níveis, e PALa com 50\% de umidade. $\mathrm{Na}$ amostra de GPH, os valores de BMS-C nos níveis 25,50 e $75 \%$ de umedecimento foram significativamente maiores do que no controle, o que indica que o condicionamento na forma de TFSA, seguido de correção de umidade, acarretou superestimativa dessa característica. Neste caso, assim como em outros trabalhos (Joergensen et al., 1990; Scheu \& Parkinson, 1994; Franzluebbers et al., 1996), a secagem poderia tornar a matéria orgânica do solo mais acessível à decomposição, além do fato de os microrganismos mortos com a secagem terem sido, talvez, prontamente atacados pelos remanescentes após o reumedecimento, o que pode ser corroborado pelos altos valores de respiração basal dessa amostra (Tabela 3), identificando-se pulsos de atividade microbiana imediatamente e 24 horas após o início de incubação (Tabela 2).

A determinação da RB na TFSA, sem a restituição do nível de umidade, acarretou, na maioria dos solos, queda abrupta na evolução de $\mathrm{CO}_{2}$ do solo, se comparado com o controle (Tabela 3 ). Após o reumedecimento, a RB foi maior do que no tratamento-con- trole, notadamente nos níveis de 50 e $75 \%$ de umidade, possivelmente associada ao fato de os microrganismos mortos com a secagem terem sido atacados pelos remanescentes, além da possibilidade de o ciclo de secagem e umedecimento da amostra ter tornado a matéria orgânica do solo mais acessível à decomposição microbiana (Joergensen et al., 1990; Franzluebbers et al., 1996). Quando a umidade foi corrigida a $25 \%$ da capacidade máxima de retenção de água, os valores de RB foram similares ao do controle, exceto nas amostras de RZ e V, que se mostraram maiores, e assim mantiveram-se nos níveis de 50 e $75 \%$ de umidade. Em relação a RB, foram detectados coeficientes de correlação significativos nos níveis de 25 e $50 \%$ de umidade, comparativamente com o tratamento-controle. Portanto, o nível de $25 \%$ de umidade mostrou-se mais adequado, para a maioria dos solos, quando visto concomitantemente com a ajuda do teste de correlação e do teste de médias (Tabela 3).

Contudo, trabalhos mais específicos necessitam ser realizados com vistas a identificar características dos solos que interfiram nos resultados da análise da BMS-C e da RB em amostras condicionadas desta forma, combinando os fatores tempo de incubação e umidade.

Tabela 3. Carbono da biomassa microbiana ( $\mu \mathrm{g}$ de carbono por $g$ de solo) e da respiração microbiana basal ( $\mu g$ de carbono- $\mathrm{CO}_{2}$ por $\mathrm{g}$ de solo, por hora) em amostras de diferentes classes de solo condicionadas na forma de terra fina seca ao ar e umedecidas a $0,25,50,75 \%$ da capacidade máxima de retenção de água e coeficientes de correlação $(\mathrm{r})^{(1)}$.

\begin{tabular}{|c|c|c|c|c|c|c|c|c|c|c|}
\hline \multirow[t]{3}{*}{ Solo ${ }^{(2)}$} & \multicolumn{5}{|c|}{ Biomassa microbiana } & \multicolumn{5}{|c|}{ Respiração microbiana basal } \\
\hline & \multirow[t]{2}{*}{ Controle $^{(3)}$} & \multicolumn{4}{|c|}{$\begin{array}{c}\text { Umidade (porcentagem em relação } \\
\text { à capacidade máxima de retenção de água) }\end{array}$} & \multirow[t]{2}{*}{ Controle $^{(3)}$} & \multicolumn{4}{|c|}{$\begin{array}{c}\text { Umidade (porcentagem em relação } \\
\text { à capacidade máxima de retenção de água) }\end{array}$} \\
\hline & & 0 & 25 & 50 & 75 & & 0 & 25 & 50 & 75 \\
\hline & -1 & & $(\mu \mathrm{g} / \mathrm{g})-$ & 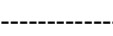 & ------------ & & & $\mu \mathrm{g} / \mathrm{g} . \mathrm{h}$ & & \\
\hline PALa & $309 a$ & $171 b$ & $421 \mathrm{a}$ & $159 \mathrm{~b}$ & $392 \mathrm{a}$ & $1,01 \mathrm{a}$ & $0,55 \mathrm{a}$ & $0,97 \mathrm{a}$ & $1,01 \mathrm{a}$ & $1,14 \mathrm{a}$ \\
\hline LVa & $334 a b$ & $116 \mathrm{bc}$ & $323 a b$ & $522 \mathrm{a}$ & $277 b$ & $0,70 \mathrm{~b}$ & $0,18 \mathrm{c}$ & $1,06 \mathrm{ab}$ & $1,31 \mathrm{a}$ & $1,16 \mathrm{ab}$ \\
\hline PE & $336 a$ & $88 b$ & $183 \mathrm{a}$ & $207 \mathrm{a}$ & $267 \mathrm{a}$ & $0,98 \mathrm{a}$ & $0,22 b$ & $1,19 \mathrm{a}$ & $1,15 \mathrm{a}$ & $1,27 \mathrm{a}$ \\
\hline PAa & $389 \mathrm{a}$ & $139 b$ & $299 a$ & $310 \mathrm{a}$ & $336 \mathrm{a}$ & $0,69 \mathrm{c}$ & $-0,04 d$ & $0,62 \mathrm{c}$ & $1,36 \mathrm{~b}$ & $1,61 \mathrm{a}$ \\
\hline $\mathrm{PVa}$ & $358 \mathrm{a}$ & $207 b$ & $501 \mathrm{a}$ & $433 a$ & $467 \mathrm{a}$ & $0,95 \mathrm{c}$ & $-0,05 \mathrm{~d}$ & $1,06 \mathrm{bc}$ & $1,61 \mathrm{ab}$ & $1,85 \mathrm{a}$ \\
\hline $\mathrm{RZ}$ & $409 b c$ & $326 \mathrm{c}$ & $609 a$ & $413 b c$ & $476 \mathrm{ab}$ & $0,81 \mathrm{~b}$ & $0,23 \mathrm{c}$ & $1,53 \mathrm{a}$ & $1,55 \mathrm{a}$ & $1,65 \mathrm{a}$ \\
\hline V & $583 \mathrm{ab}$ & $226 \mathrm{c}$ & $766 a$ & $722 \mathrm{ab}$ & $553 b$ & $0,67 \mathrm{~d}$ & $0,04 \mathrm{e}$ & $1,56 \mathrm{~b}$ & $1,24 \mathrm{c}$ & $1,98 \mathrm{a}$ \\
\hline $\mathrm{O}$ & $562 \mathrm{ab}$ & $321 \mathrm{c}$ & $729 a$ & $618 \mathrm{ab}$ & $527 \mathrm{~b}$ & $1,75 \mathrm{~b}$ & $0,20 \mathrm{c}$ & $1,86 \mathrm{ab}$ & $1,83 b$ & $2,19 \mathrm{a}$ \\
\hline PL & $299 a$ & $73 b$ & $153 \mathrm{ab}$ & $107 \mathrm{ab}$ & $143 a b$ & $0,79 \mathrm{a}$ & $0,35 \mathrm{a}$ & $0,78 \mathrm{a}$ & $0,83 a$ & $1,05 \mathrm{a}$ \\
\hline GPH & $826 \mathrm{~b}$ & $666 \mathrm{~b}$ & $1.117 \mathrm{a}$ & $1.231 \mathrm{a}$ & $1.324 \mathrm{a}$ & $1,19 \mathrm{a}$ & $-0,38 b$ & $1,48 \mathrm{a}$ & $1,33 \mathrm{a}$ & $1,44 \mathrm{a}$ \\
\hline $\mathrm{r}$ & 1,00 & $0,87 * * *$ & $0,89 * * *$ & $0,92 * * *$ & $0,89 * * *$ & 1,00 & $0,02^{\text {ns }}$ & $0,43 *$ & $0,33^{*}$ & $0,30^{\mathrm{ns}}$ \\
\hline
\end{tabular}

(1)Valores em uma mesma linha seguidos de letras iguais não diferem pelo teste de Tukey, a 5\% de probabilidade. (2) PALa: Podzólico Amarelo Latossólico álico; LVa: Latossolo Vemelho-Amarelo álico; PE: Podzólico Vermelho-Escuro; PAa: Podzólico Amarelo álico; PVa: Podzólico Vermelho-Amarelo álico; RZ: Rendizina; V: Vertissolo; O: Orgânico; PL: Planossolo arenoso; GPH: Glei Pouco Húmico. ${ }^{(3)}$ Amostras que não sofreram dessecação e com umidade corrigida a $60 \%$ da capacidade máxima de retenção. $* * *, * *$ e $*$ Significativo a $0,1 \%$, a $1 \%$ e a $5 \%$ de probabilidade, respectivamente. 


\section{Conclusões}

1. O condicionamento, de curta duração, de amostras de solos na forma de TFSA, procedendo-se à fumigação para a análise da BMS-C imediatamente, 24 ou 72 horas após o reumedecimento, mostra-se viável na maioria dos solos avaliados.

2. O efeito do reumedecimento da TFSA na BMS-C depende da classe de solo mas, o uso de teores de 25 a $75 \%$ da capacidade máxima de retenção de água mostra-se viável na maioria dos solos avaliados.

3. Amostras de solo condicionadas na forma de TFSA, com a umidade corrigida a $25 \%$ da capacidade máxima de retenção de água, apresentam valores de RB similares aos do controle, na maioria dos solos, considerando-se a medição da respiração logo após a correção da umidade.

\section{Referências}

BADALUCCO, L.; DE CESARE, F.; GREGO, S.; LANDI, L. Do physical properties of soil affect chloroform efficiency in lysin microbial biomass? Soil Biology \& Biochemistry, Oxford, v. 29, n. 7, p. 1135-1142, 1997.

BOTNER, P. Response of microbial biomass to alternate moist and dry conditions in a soil incubated with ${ }^{14} \mathrm{C}$ and ${ }^{15} \mathrm{~N}$-labeled plant material. Soil Biology \& Biochemistry, Oxford, v. 17, n. 3, p. 329-337, 1985.

COLORES, G. M.; SCHMIDT, S. K.; FISK, M. C. Estimating the biomass of microbial functional groups using rates of growth-related soil respiration. Soil Biology \& Biochemistry, Oxford, v. 28, n. 12, p. 1569-1577, 1996.

DE-POLLI, H.; GUERRA, J. G. M. C, N e P na biomassa microbiana do solo. In: SANTOS, G. A.; CAMARGO, F. A. O. (Ed.). Fundamentos da matéria orgânica do solo: ecossistemas tropicais e subtropicais. Porto Alegre: Genesis, 1999. p. 389-411.

EMBRAPA. Serviço Nacional de Levantamento e Conservação de Solos (Rio de Janeiro, RJ). Manual de métodos de análise de solo. Rio de Janeiro, 1979. Não paginado.

FRANZLUEBBERS, A. J. Potential $\mathrm{C}$ and N mineralization and microbial biomass from intact and increasingly disturbed soils of varying texture. Soil Biology \& Biochemistry, Oxford, v. 31, n. 8, p. 1083-1090, 1999.
FRANZLUEBBERS, A. J.; HANEY, R. L.; HONEYCUTT, C. W.; SCHOMBERG, H. H.; HONS, F. M. Flush of carbon dioxide following rewetting of dried soil relates to active organic pools. Soil Science Society of America Journal, Madison, v. 64, n. 2, p. 613-623, 2000.

FRANZLUEBBERS, A. J.; HANEY, F. M.; ZUBERER, D. A. Determination of microbial biomass and nitrogen mineralization following rewetting of dried soil. Soil Science Society of America Journal, Madison, v. 60, n. 4, p. 1133-1139, 1996.

GESTEL, M. van; LADD, J. N.; AMATO, M. Microbial biomass responses to seasonal change and imposed drying regimes at increasing depths of undisturbed topsoil profiles. Soil Biology \& Biochemistry, Oxford, v. 24, n. 2, p. 103-111, 1992.

GESTEL, M. van; MERCKX, R.; VLASSAK, K. Microbial biomass responses to soil drying and rewetting: the fate of fast and slow-growing microorganisms in soils from different climates. Soil Biology \& Biochemistry, Oxford, v. 25, n. 2, p. 109-123, 1993.

HORWATH, W. R.; PAUL, E. A. Microbial biomass. In: WEAVER, R. W.; ANGLE, S.; BOTTENLEY, P.; BEZDICEK, D.; SMITH, S.; TABATABAI, A.; WOLLUM, A. (Ed.). Methods of soil analysis: microbiological and biochemical properties. Madison: Soil Science Society of America, 1994. Part 2, p. 753-773. (Book Series, 5).

JENKINSON, D. S.; POWLSON, D. S. The effects of biocidal on metabolism in soil. V. Method for measuring soil biomass. Soil Biology \& Biochemistry, Oxford, v. 8, n. 3, p. 209-213, 1976.

JOERGENSEN, R. G.; BROOKES, P. C.; JENKINSON, D. S. Survival of the soil microbial biomass at elevated temperatures. Soil Biology \& Biochemistry, Oxford, v. 22 , n. 8 , p. 1129-1136, 1990.

KIEFT, T. L.; SOROKER, E.; FIRESTONE, M. K. Microbial biomass response to a rapid increase in water potential when dry soil is wetted. Soil Biology \& Biochemistry, Oxford, v. 19, n. 2, p. 119-126, 1987.

LUNDQUIST, E. J.; JACKSON, L. E.; SCOW, K. M. Wet-dry cycles affect dissolved organic carbon in two California agricultural soils. Soil Biology \& Biochemistry, Oxford, v. 31, n. 7, p. 1031-1038, 1999.

RODRIGUES, E. F. da G.; GUERRA, J. G. M.; ALMEIDA, D. L.; DE-POLLI, H. Biomassa microbiana 
de carbono de solos de Itaguaí (RJ): comparação entre os métodos fumigação-incubação e fumigação-extração. Revista Brasileira de Ciência do Solo, Campinas, v. 18, n. 3, p. 427-432, 1994.

SCHEU, S.; PARKINSON, D. Changes in bacterial and fungal biomass $\mathrm{C}$, bacterial and fungal biovolume and ergosterol content after drying, remoistening and incubation of different layers of cool temperate forest soils. Soil Biology \& Biochemistry, Oxford, v. 26, n. 11, p. 1515-1525, 1994.

SPARLING, P. G. Ratio of microbial biomass carbon to soil organic carbon as a sensitive indicator of changes in soil organic matter. Australian Journal of Soil Research, Collingwood, v. 30, p. 95-207, 1992.

SRIVASTAVA, S. C. Microbial contribution to extractable $\mathrm{N}$ and $\mathrm{P}$ after air-drying of dry tropical soils. Biology and Fertility of Soils, Berlin, v. 26, n. 1, p. 31-34, 1998.
VANCE, E. D.; BROOKES, P. C.; JENKINSON, D. S. An extraction method for measuring soil microbial biomass C. Soil Biology \& Biochemistry, Oxford, v. 19, n. 6 , p. 703-707, 1987.

WARDLE, D. A. A comparative assessment of factors which influence microbial biomass carbon and nitrogen levels in soils. Biological Reviews, Cambridge, Inglaterra, v. 67, p. 321-358, 1992.

WARDLE, D. A. Controls of temporal variability of the soil microbial biomass: a global-scale synthesis. Soil Biology \& Biochemistry, Oxford, v. 30, n. 13, p. 1627-1637, 1998.

WARDLE, D. A.; GHANI, A. A critique of the microbial metabolic quotient $\left(\mathrm{qCO}_{2}\right)$ as a bioindicator of disturbance and ecosystem development. Soil Biology \& Biochemistry, Oxford, v. 27, n. 12, p. 1601-1610, 1995. 